\title{
Fuzzy Evidential Reasoning Approach for LCMS Competitiveness Evaluation under Incomplete Information
}

\author{
Bengang Gong, ${ }^{1,2}$ Xiaoqi Zhang, ${ }^{1}$ Dandan Guo, ${ }^{1}$ and Yunmiao Gui ${ }^{1}$ \\ ${ }^{1}$ School of Management Engineering, Anhui Polytechnic University, Wuhu, Anhui 241000, China \\ ${ }^{2}$ School of Management, Fudan University, Shanghai 200433, China \\ Correspondence should be addressed to Bengang Gong; bggong@ahpu.edu.cn
}

Received 22 September 2014; Accepted 6 February 2015

Academic Editor: Andreas Oberheitmann

Copyright (c) 2015 Bengang Gong et al. This is an open access article distributed under the Creative Commons Attribution License, which permits unrestricted use, distribution, and reproduction in any medium, provided the original work is properly cited.

\begin{abstract}
In order to evaluate scientifically low carbon manufacturing system (LCMS) competitiveness under incomplete information, this paper, using fuzzy mathematics theory and evidential reasoning approach, proposes an evaluation method. Firstly, through fuzzy evaluation the influence factors of LCMS competitiveness are characterized by a set of evaluation grades. Secondly, the analytical evidential theory algorithms are used to aggregate the evaluation grades of multiple influence factors, and the assessed values of LCMS competitiveness are obtained under each evaluation index and the system overall goal. According to the evaluation value, the key influence factors of LCMS competitiveness, which need to be improved and enhanced, are found. Lastly, a numerical example is provided.
\end{abstract}

\section{Introduction}

Manufacturing enterprises, as a high discharge and high pollution industry, also have high energy consumption, which occupies a larger proportion in the national energy consumption [1]. Low carbon level of manufacturing systems has turned into a competitive power and become a new important index to measure national and regional competitiveness. Consequently, the evaluation of low carbon manufacturing system (LCMS) competitiveness is increasingly important and has become a new research direction for the future manufacturing system theory.

As the operation process for LCMS has the dynamic characteristics, decision makers in the evaluation of LCMS competitiveness often face some uncertainty situations such as lack of decision data and incomplete information. Fuzzy evidence reasoning theory, as a reasoning method dealing effectively with such uncertainty information as randomness, and fuzziness, interval, now has become a powerful tool for expressing and synthesizing uncertainty information in fault diagnosis, target recognition, data fusion, and reliability analysis of mechanical system $[2,3]$.
This paper applies fuzzy evidence reasoning theory to the evaluation of LCMS competitiveness under incomplete information and then proposes an evaluation method of LCMS competitiveness based on fuzzy evidence reasoning model. Section 2 reviews the literatures related to this research. Section 3 designs the evaluation index system, the indicator system. Section 4 gives the evaluation model based on fuzzy evidential reasoning. Section 5 gives a numerical example. Finally, this paper is concluded in Section 6.

\section{Literature Review}

In recent years, with the global climate change, low carbon economy has got more and more attention, and low carbon manufacturing starts to become a new research hotspot. Current researches can be sorted into three aspects.

(1) Theories and methods for low carbon manufacturing and optimization and design of LCMS: Tridech and Cheng defined low carbon manufacturing and analyzed how LCMS can effectively use energy and resources when reducing carbon emissions intensity 
in the manufacturing process [4]. Rothenberg et al. investigated energy saving and emission through lean workshop and in productive process and focus on the analysis of energy flow tracking problem for manufacturing system [5]. Linton et al. researched into the production optimization decisions of a single enterprise under permits and trading mechanism as well as the dynamic evaluation of production system operation [6]. Benjaafar et al. investigated how the quick response thought reduces energy use efficiency and increases carbon emissions [7]. Venkat and Wakeland, through an example, analyzed energy consumption and carbon emissions of supply chain under lean production structure and unlean production structure [8]. Tapio et al. examined how "zero inventory" in lean production, as a management mode, is advantageous to the improvement of the efficiency of production process, but frequent transportation would cause a decline in energy efficiency and an increase in carbon emission [9]. Flapper et al., under the situation of improving energy efficiency through products recycling, proposed an optimization decision method for the production operation system of supply chain enterprises [10].

(2) Carbon flow and energy consumption calculation for LCMS: Ball et al. put forward a concept of "zero carbon manufacturing" and establish a system framework to analyze the relationship between the input and output of carbon flow and discuss the possibility of zero carbon manufacturing [11]. Matthews et al., based on life cycle evaluation, proposed an evaluation analysis method of supply chain carbon emissions and carbon footprint [12]. Jeswiet and Kara put forward a carbon emission index and a calculating method for carbon emission of the power consumption of parts manufacturing in power plants [13]. Song and Lee presented a design method of low carbon product system based on BOM of emissions for embedded greenhouse gas [14]. Tridech and Cheng, based on the analysis of characteristics of LCMS, provided some key factors and the calculating method affecting the energy consumption law in the machining process [15]. Vijayaraghavan and Dornfeld researched into a real-time monitoring technology of energy consumption of machine tools and raised an energy data processing method of manufacturing system based on event stream processing technology [16]. Gutowski et al. put forward an enterprise energy consumption calculation method based on power demand side management [17].

(3) LCMS competitiveness evaluation and carbon emission reduction strategies: Mckinnon, from the perspective of supply chain, pointed out the difficulties and the problems of calculating carbon footprint and implementing carbon label and analyzes the potential benefits for carbon footprint and carbon labeling [18]. Perry et al. pointed out that the whole process integration system technology for process industries and local energy industries is more effective in reducing carbon footprint than in improving energy efficiency [19]. Demailly and Quirion, taking the iron and steel industry as an example, discussed the impact of European carbon emissions trading scheme upon the industry production and income [20].

For global climate change's pressure, various countries propose in succession specific targets for carbon emissions reduction. Under this background, many issues such as the optimization of LCMS, the carbon flow characteristic analysis for manufacturing system, carbon emissions (carbon footprint) calculation, and carbon emissions reduction strategies and methods have got special attention. However, the problem of LCMS competitiveness evaluation has rarely been mentioned. In real life, the manufacturing system is a very complex uncertainty system. Under the uncertain environment, the research on competitiveness evaluation of LCMS is of great significance, both in theory and in practice.

\section{The Design of the Evaluation Index System}

There exists some difference between low carbon manufacturing and such concepts as green manufacturing, environmentally benign manufacturing, sustainable manufacturing, and so forth. Low carbon manufacturing, integrating the whole life cycle and considering comprehensively resources and environment efficiency, regards the carbon emissions reduction as the main line or its highlight, and so it belongs to the category of green manufacturing and sustainable manufacturing. LCMS is an input and output system, which shifts all kinds of manufacturing resources and energy into products, to ensure economic effectiveness and achieve carbon emissions reduction. It involves the whole life cycle of products (including market analysis, product design, process planning, machining process, transportation, product sales and after-sales service, and recycling) or partial link [21]. LCMS competitiveness puts more emphasis on the coordinated and sustainable development between economy and environment based on traditional manufacturing system competitiveness.

There are many factors affecting the LCMS competitiveness. Based on the TQCF model of making decision attribute (Chryssolouris, 1992) [22], this paper takes system energy consumption and carbon emission into consideration. In other words, major competitive factors influencing LCMS are time, quality, cost, and carbon emission.

(1) Time (T): it means the reaction speed of LCMS to the market, which mainly includes $T_{1}$ from the starting of the market demand to product design time, from product design to design completion time $T_{2}$, and from product design completion to the time that customer demand is satisfied.

(2) Quality $(Q)$ : it means the quality of the products made of LCMS, which mainly includes the product design quality $Q_{1}$, manufacturing quality $Q_{2}$, and using quality $Q_{3}$. 
(3) Cost $(C)$ : it means the economic consumption of products made of LCMS, which mainly includes the design cost $C_{1}$, the raw materials cost $C_{2}$, energy consumption cost $C_{3}$, manufacturing producing cost $C_{4}$, and logistics cost $C_{5}$.

(4) Carbon emission $(E)$ : it means carbon emission levels of products made of LCMS. Carbon emission level of LCMS comes mainly from material consumption $E_{1}$ and energy consumption $E_{2}$.

\section{The Proposed Approach}

4.1. The Description of Problem. Suppose $A$ is an evaluation object of LCMS competitiveness; $f_{i}^{j}(i=1,2, \ldots, L ; j=$ $1,2, \ldots, M)$ is the evaluation index of $i$ of layer $j$ for LCMS competitiveness; $w_{i}^{j}(i=1,2, \ldots, L ; j=1,2, \ldots, M)$ is the weight of index $f_{i}^{j}$, respectively, which meets $w_{i}^{j} \geq$ $0, \sum_{i=1}^{L} w_{i}^{j}=1 ; H_{n}(n=1,2, \ldots, N)$ are the evaluation grades of each index given by decision makers; namely, $\left(H_{1}, H_{2}, H_{3}, H_{4}, H_{5}\right)=$ (stronger, strong, ordinary, weak, weaker). If evaluation grade for competitiveness evaluation index $f_{i}^{j}$ is $H_{1}$, it denotes that competitiveness of object $A$ in the aspect of attribute indexes is stronger. If evaluation grade for the index $f_{i}^{j}$ is $H_{3}$, it denotes that competitiveness is ordinary, and so on. $\beta_{n, i}(A)$ shows that evaluation grades of evaluation object on the index $f_{i}^{j}$ are confidence degree of $H_{n}$; namely, $S_{n, i}\left(f_{i}^{j}(A)\right)=\left\{\left(H_{n}, \beta_{n, i}(A)\right), n=1,2, \ldots, N\right\}$ $\left(0 \leq \beta_{n, i}(A) \leq 1\right)$; the bigger value of $\beta_{n, i}(A)$ means the bigger degrees of belief given by decision makers. If $\sum_{n=1}^{N} \beta_{n, i}(A)=1$, it means that the degree of belief given by decision makers is $100 \%$, which is a complete evaluation. If $\sum_{n=1}^{N} \beta_{n, i}(A)<1$, it means that the degree of belief given by decision makers is less than 1 , which is an incomplete evaluation. If $\sum_{n=1}^{N} \beta_{n, i}(A)=0$, it means that the degree of belief given by decision makers is equal to 0 , which shows that decision makers cannot make any evaluation of object $A$ due to the unknown [23].

4.2. Fuzzy Evidential Reasoning Model. For an evaluation of LCMS competitiveness in uncertain environment, by using fuzzy evaluation technology, the paper gives the evaluation grades and belief degree of influence index for LCMS competitiveness. Then different evaluation grades are synthesized according to evidential reasoning algorithm (Yang et al., 2002). Finally, the competitive evaluation values of different index and total evaluation of LCMS are concluded [23]. The specific evaluation process is as follows.

Step 1. Judge the degree of belief on the competitiveness of the bottom index. Based on historical data, knowledge, and experience, decision maker judges the belief degree affecting the bottom index $f_{i}^{j}(i=1,2, \ldots, L ; j=1,2, \ldots, M)$ of LCMS competitiveness and gives different evaluation grade.

Step 2. Construct the basic probability assignment ( $b p a$ ) function. All indexes for each level $f_{i}^{j}(i=1,2, \ldots, L ; j=$ $1,2, \ldots, M)$ affecting the LCMS competitiveness are seen as the evidence of evidential reasoning theory, and the evaluation grade of $H=\left\{H_{n}, n=1, \ldots, N\right\}$ is seen as the discernment frame. Suppose $f_{i}^{j}$ is the $i$ th evidence of the $j$ th layer; the basic probability assignment functions are defined as follows:

$$
\begin{aligned}
& m_{n, i}=m_{i}\left(H_{n}\right)=w_{i} \beta_{n, i}(A), \\
& n=1,2, \ldots, N ; i, j=1, \ldots, L, \\
& m_{H, i}=m_{i}(H)=1-\sum_{n=1}^{N} m_{n, i}=1-w_{i} \sum_{n=1}^{N} \beta_{n, i}(A), \\
& \bar{m}_{H, i}=\bar{m}_{i}(H)=1-w_{i}, \quad i=1, \ldots, L, j, \ldots, L, \\
& \widetilde{m}_{H, i}=\widetilde{m}_{i}(H)=w_{i}\left(1-\sum_{n=1}^{N} \beta_{n, i}(A)\right), \\
& m_{H, i}=\bar{m}_{H, i}+\widetilde{m}_{H, i}, \\
& \sum_{i=1}^{L} w_{i}=1,
\end{aligned}
$$

where $m_{n, i}$ denotes the basic probability mass of the LCMS competitiveness being assessed to grade $H_{n}$ on the index $f_{i}^{j}$ and $m_{H}$ is unassigned basic probability mass, including two parts: $\bar{m}_{H, i}$ and $\bar{m}_{H, i}$, where $\bar{m}_{H, i}$ is caused by the index weights and $\widetilde{m}_{H, i}$ by the incompleteness of evaluation on indexes for the LCMS competitiveness.

Step 3. Apply the hierarchical recursion algorithm of evidential reasoning theory to synthesizing of all kinds of evidence. According to Steps 1 and 2, decision maker constructs the basic probability assignment function of bottom indexes. According to Dempster's rule of combination, the comprehensive evaluation grade and belief degrees of LCMS competitiveness are obtained by using the following calculation formula [23]:

$$
\begin{aligned}
& \left\{H_{n}\right\}: m_{n}=k\left[\prod_{i=1}^{L}\left(m_{n, i}+\bar{m}_{H, i}+\widetilde{m}_{H, i}\right)\right. \\
& \left.-\prod_{i=1}^{L}\left(\bar{m}_{H, i}+\widetilde{m}_{H, i}\right)\right], \quad n=1, \ldots, N, \\
& \{H\}: \widetilde{m}_{H}=k\left[\prod_{i=1}^{L}\left(\bar{m}_{H, i}+\widetilde{m}_{H, i}\right)-\prod_{i=1}^{L} \bar{m}_{H, i}\right], \\
& \{H\}: \bar{m}_{H}=k\left[\prod_{i=1}^{L} \bar{m}_{H, i}\right],
\end{aligned}
$$


TABLE 1: Evaluation grade of LCMS competitiveness.

\begin{tabular}{|c|c|c|c|c|c|c|}
\hline \multicolumn{2}{|l|}{ Evaluation grade } & $H_{1}$ & $\mathrm{H}_{2}$ & $H_{3}$ & $H_{4}$ & $H_{5}$ \\
\hline \multicolumn{2}{|c|}{ Meaning of the different evaluation grade } & Stronger & Strong & Ordinary & Weak & Weaker \\
\hline \multirow{2}{*}{ Competitiveness value of evaluation grade $\left(P\left(H_{n}\right)\right)$} & Percentage interval value & $90-100$ & $80-90$ & $70-80$ & $60-70$ & Under 60 \\
\hline & Midvalue of class interval & 95 & 85 & 75 & 65 & 30 \\
\hline
\end{tabular}

$$
\begin{aligned}
& k=\left[\sum_{n=1}^{N} \prod_{i=1}^{L}\left(m_{n, i}+\bar{m}_{H, i}+\widetilde{m}_{H, i}\right)-(N-1)\right. \\
& \left.\quad \cdot \prod_{i=1}^{L}\left(\bar{m}_{H, i}+\widetilde{m}_{H, i}\right)\right]^{-1}, \\
& \left\{H_{n}\right\}: \beta_{n}=\frac{m_{n}}{1-\bar{m}_{H}}, \quad n=1, \ldots, N, \\
& \{H\}: \beta_{H}=\frac{\widetilde{m}_{H}}{1-\bar{m}_{H}},
\end{aligned}
$$

where $\beta_{n}$ represents the belief degrees of the LCMS competitiveness being assessed to grade $H_{n}$ and $\beta_{H}$ is the degrees of belief unassigned to any individual evaluation grade after all the $L$ basic attributes have been assessed. It denotes the degree of incompleteness in the evaluation generated.

Step 4. Calculate evaluation value of the LCMS competitiveness [23].

With lots of generality, as shown in Table 1, suppose the highest preferred grade having the highest utility is $H_{1}$ and the least preferred grade having the lowest utility is $H_{5}$. Then the maximum, minimum, and average utilities of object $A$ are given by

$$
\begin{aligned}
P_{\min }(A)= & \sum_{n=1}^{N-1} \beta_{n}(A) P\left(H_{n}\right) \\
& +\left(\beta_{N}(A)+\beta_{H}(A)\right) P\left(H_{N}\right), \\
P_{\max }(A)= & \left(\beta_{1}(A)+\beta_{H}(A)\right) P\left(H_{1}\right) \\
& +\sum_{n=2}^{N} \beta_{n}(A) P\left(H_{n}\right) .
\end{aligned}
$$
follows

The evaluation value of LCMS competitiveness is as

(1) When $\sum_{n=1}^{N} \beta_{n}(A)=1$, then the evaluation value of object $A$ is a point value; that is, $P(A)=$ $\sum_{n=1}^{N} \beta_{n}(A) P\left(H_{n}\right)$.

(2) When $\sum_{n=1}^{N} \beta_{n}(A)<1$, then the evaluation value of object $A$ is an interval; that is, $\left[P_{\min }(A), P_{\max }(A)\right]$, where the average assessed value of object $A$ competitiveness is $P_{\text {aver }}(A)=(1 / 2)\left(P_{\min }(A)+P_{\max }(A)\right)$.

\section{A Numerical Example}

In this section, we give an example to illustrate the evaluation of LCMS competitiveness based on fuzzy evidential reasoning model. According to Section 3, we construct an index system of LCMS competitiveness (see Table 2).

(1) Determine the index weight of each layer and the belief degree $S_{n, i}\left(f_{i}(A)\right)$ of bottom $H_{n}(n=1,2, \ldots, N)$ (see Table 2), where $w_{i}^{j}(i=1,2, \ldots, L ; j=1,2, \ldots, M)$ value is obtained by applying AHP (Analytic Hierarchy Process) method proposed by Saaty [24]; the value $S_{n, i}\left(f_{i}^{j}(A)\right)=$ $\left\{\left(H_{n}, \beta_{n, i}(A)\right), n=1,2, \ldots, N\right\}$ is directly given according to decision makers' experience and preference.

(2) With the application of (2), the values of belief degree of each layer are synthesized from the bottom index (second index). Obtain the evaluation belief values of the first level indexes by synthesizing the evaluation belief values of the second level (see Table 2). Similarly, the belief values of evaluation grade for first level indexes $T, Q, C$, and $E$ are synthesized, and then we get the values of belief degree for the total target evaluation grade (see Table 3 ).

Obviously, according to (3), competitive evaluation value of object $A$ on indexes $C$ and $E$ is a point value, that is, $P(A)$; other indexes and total goal are interval value, that is, $\left[P_{\min }(A), P_{\max }(A)\right]$. Namely, the assessed values of the competitiveness are obtained under each index and total goal as follows.

$T:\left[P_{\min }(A), P_{\max }(A)\right]=[77.97,80.037]$, and the average assessed value of the competitiveness evaluation value for evaluation object $A$ is 79.0035 , and the degree of uncertainty is 2.067 .

Q: $\left[P_{\min }(A), P_{\max }(A)\right]=[69.022,78.044]$, and the average assessed value of the competitiveness evaluation value for evaluation object $A$ is 73.533 , and the degree of uncertainty is 9.022 .

$C: P(A)=84.243$, and the assessed value of the competitiveness evaluation value for evaluation object $A$ is 84.243 .

$E: P(A)=60.6635$, and the assessed value of the competitiveness evaluation value for evaluation object $A$ is 60.6635 .

Total goal: $\left[P_{\min }(A), P_{\max }(A)\right]=[71.609,74.0725]$, and the average for the competitiveness evaluation value is 72.8408 .

(3) Analysis of the results is as follows. According to the above data, the general evaluation value of LCMS is 72.8408. The result shows that the system competitiveness level is the general grade, but in general it is still low, 
TABLE 2: The index system of LCMS competitiveness.

\begin{tabular}{|c|c|c|c|c|c|}
\hline \multirow[b]{2}{*}{ Target layer } & \multicolumn{2}{|c|}{ First level indexes } & \multicolumn{3}{|c|}{ Second index } \\
\hline & Name & Weight & Name & Weight & Evaluation grade \\
\hline \multirow{12}{*}{$\begin{array}{l}\text { LCMS } \\
\text { competitiveness }(A)\end{array}$} & \multirow{3}{*}{$\begin{array}{l}\text { Time } \\
(T)\end{array}$} & \multirow{3}{*}{0.25} & $\begin{array}{l}\text { From the starting of the market demand to } \\
\text { product design time }\left(T_{1}\right)\end{array}$ & 0.35 & $\left\{\left(H_{1}, 0.6\right),\left(H_{2}, 0.4\right)\right\}$ \\
\hline & & & $\begin{array}{l}\text { From product design to design completion } \\
\text { time }\left(T_{2}\right)\end{array}$ & 0.30 & $\left\{\left(H_{3}, 1.0\right)\right\}$ \\
\hline & & & $\begin{array}{l}\text { From product design completion to the time } \\
\text { that customer demand is satisfied }\left(T_{3}\right)\end{array}$ & 0.35 & $\left\{\left(H_{3}, 0.6\right),\left(H_{4}, 0.3\right)\right\}$ \\
\hline & \multirow{4}{*}{$\begin{array}{l}\text { Quality } \\
\text { (Q) }\end{array}$} & \multirow{4}{*}{0.25} & Design quality $\left(Q_{1}\right)$ & 0.25 & $\left\{\left(H_{2}, 1.0\right)\right\}$ \\
\hline & & & Manufacturing quality $\left(Q_{2}\right)$ & 0.35 & $\left\{\left(H_{3}, 0.8\right)\right\}$ \\
\hline & & & Using quality $\left(Q_{3}\right)$ & 0.40 & $\left\{\left(H_{3}, 0.3\right),\left(H_{4}, 0.5\right)\right\}$ \\
\hline & & & Design cost $\left(C_{1}\right)$ & 0.25 & $\left\{\left(H_{2}, 1.0\right)\right\}$ \\
\hline & \multirow{3}{*}{$\begin{array}{l}\text { Cost } \\
(C)\end{array}$} & \multirow{3}{*}{0.20} & Raw material cost $\left(C_{2}\right)$ & 0.25 & $\left\{\left(H_{3}, 1.0\right)\right\}$ \\
\hline & & & Energy consumption cost $\left(C_{3}\right)$ & 0.30 & $\left\{\left(H_{1}, 0.5\right),\left(H_{2}, 0.5\right)\right\}$ \\
\hline & & & Logistics cost $\left(C_{4}\right)$ & 0.20 & $\left\{\left(H_{2}, 1.0\right)\right\}$ \\
\hline & \multirow{2}{*}{$\begin{array}{l}\text { Carbon } \\
\text { emission } \\
(E)\end{array}$} & \multirow{2}{*}{0.30} & Material consumption $\left(E_{1}\right)$ & 0.45 & $\left\{\left(H_{4}, 0.6\right),\left(H_{5}, 0.4\right)\right\}$ \\
\hline & & & Energy consumption $\left(E_{2}\right)$ & 0.55 & $\left\{\left(H_{4}, 1.0\right)\right\}$ \\
\hline
\end{tabular}

TABLE 3: Belief degrees and evaluation grade for LCMS competitiveness and their factors.

\begin{tabular}{lcccccc}
\hline \multirow{2}{*}{ Factors/the whole object $A$} & \multicolumn{5}{c}{ Belief degrees assessed to grades $H_{n}$ and $H$} \\
& $H_{1}$ & $H_{2}$ & $H_{3}$ & $H_{4}$ & $H_{5}$ \\
\hline Time $(T)$ & 0.2007 & 0.1339 & 0.5384 & 0.0952 & 0 \\
Quality $(Q)$ & 0 & 0.2276 & 0.4328 & 0.2008 & 0 & 0.0318 \\
Cost $(C)$ & 0.1364 & 0.6515 & 0.2121 & 0 & 0 & 0.1388 \\
Carbon emission $(E)$ & 0 & 0 & 0 & 0.8761 & 0.1239 \\
\hline LCMS competitiveness $(A)$ & 0.0715 & 0.2110 & 0.2869 & 0.3556 & 0.0371 \\
\hline
\end{tabular}

which indicates that the system competitiveness remains to be further improved. At the same time, we also see that there are some uncertainties in the evaluation of systemic competitiveness; that is, the degree of uncertainty for the system is $P_{\max }(A)-P_{\min }(A)=2.4635$. The more the information and data related to the system competitiveness acquired, the smaller the uncertainty of evaluation process. According to competitiveness evaluation value in Table 2 and $T, Q, C$, and $E$, the competitiveness of LCMS evaluation index $E$ is the weakest, and $Q$ is weaker, but $C$ is the strongest in competitiveness. It shows that $E$ is the key factor which results in the fact that system competitiveness is weak. Therefore, in order to improve the competitiveness of LCMS, the primary work is to improve the competitiveness of system $E$ and then Q.

\section{Conclusions}

Evaluation of LCMS competitiveness under uncertain environment is a very complicated job, in which there are many uncertainty factors, and the information and data related to the evaluation are often ambiguous and incomplete. Therefore, it is difficult to use some traditional evaluation models based on probability theory and mathematical statistics.
Comparing our method with the others, we have found that it uses the belief degree, instead of a single numerical grading, to express the distribution of the evaluation grade. Secondly, it can reveal uncertain information. Moreover, with the method, the model construction difficulties due to the incomplete information and the lack of data can also be avoided. Meanwhile, experts' experience and knowledge are considered in the model construction process. Lastly, the numerical example shows that this method is able to reflect properly the behavior of LCMS and helps to find out the key factors that need improving so as to enhance the system competitiveness. In a word, our research offers a reference to the formulation of LCMS competitiveness strategy and so the improvement in LCMS competitiveness.

\section{Conflict of Interests}

The authors declare that there is no conflict of interests regarding the publication of this paper.

\section{Acknowledgments}

This work was financially supported by Natural Science Foundation of China (71171002), China Postdoctoral Science 
Foundation (2014M551335), and Humanities and Social Science Foundation of Ministry of Education (13YJA630021).

\section{References}

[1] W. D. Nordhaus, "A review of the stern review on the economics of climate change," Journal of Economic Literature, vol. 45, no. 3 , pp. 686-702, 2007.

[2] K. Mokhtari, J. Ren, C. Roberts, and J. Wang, "Decision support framework for risk management on sea ports and terminals using fuzzy set theory and evidential reasoning approach," Expert Systems with Applications, vol. 39, no. 5, pp. 5087-5103, 2012.

[3] J.-Q. Wang, R.-R. Nie, H.-Y. Zhang, and X.-H. Chen, "Intuitionistic fuzzy multi-criteria decision-making method based on evidential reasoning," Applied Soft Computing Journal, vol. 13, no. 4, pp. 1823-1831, 2013.

[4] S. Tridech and K. Cheng, "Low carbon manufacturing: characterization, theoretical models and implementation," in Proceedings of the 6th International Conference on Manufacturing Research (ICMR '08), Uxbridge, UK, 2008.

[5] S. Rothenberg, F. K. Pil, and J. Maxwell, "Lean, green, and the quest for superior environmental performance," Production and Operations Management, vol. 10, no. 3, pp. 228-243, 2001.

[6] J. D. Linton, R. Klassen, and V. Jayaraman, "Sustainable supply chains: an introduction," Journal of Operations Management, vol. 25, no. 6, pp. 1075-1082, 2007.

[7] S. Benjaafar, Y. Z. Li, and M. Daskin, "Carbon footprint and the management of supply chains: insights from simple models," Working Paper, 2009.

[8] K. Venkat and W. Wakeland, "Is lean necessarily green?" in Proceedings of the 50th Annual Meeting of the ISSS, Rohnert Park, Calif, USA, 2006.

[9] P. Tapio, D. Banister, J. Luukkanen, J. Vehmas, and R. Willamo, "Immaterialisation, dematerialisation and decarbonisation in the EU15 between 1970 and 2000," Energy Policy, vol. 35, no. 1, pp. 433-451, 2007.

[10] S. D. P. Flapper, J. A. van Nunen, and L. N. van Wassenhove, Managing Closed-Loop Supply Chains, Springer, New York, NY, USA, 2005.

[11] P. D. Ball, S. Evans, A. Levers, and D. Ellison, "Zero carbon manufacturing facility-towards integrating material, energy, and waste process flows," Journal of Engineering Manufacture, vol. 223, no. 9, pp. 1085-1096, 2009.

[12] H. S. Matthews, C. T. Hendrickson, and C. L. Weber, "The importance of carbon footprint estimation boundaries," Environmental Science and Technology, vol. 42, no. 16, pp. 5839-5842, 2008.

[13] J. Jeswiet and S. Kara, "Carbon emissions and CES in manufacturing," CIRP Annals-Manufacturing Technology, vol. 57, no. 1, pp. 17-20, 2008.

[14] J.-S. Song and K.-M. Lee, "Development of a low-carbon product design system based on embedded GHG emissions," Resources, Conservation and Recycling, vol. 54, no. 9, pp. 547$556,2010$.

[15] S. Tridech and K. Cheng, "Low Carbon Manufacturing: characterisation, theoretical models and implementation," International Journal of Manufacturing Research, vol. 6, no. 2, pp. 110121, 2011.

[16] A. Vijayaraghavan and D. Dornfeld, "Automated energy monitoring of machine tools," CIRP Annals-Manufacturing Technology, vol. 59, no. 1, pp. 21-24, 2010.
[17] T. G. Gutowski, M. S. Branham, J. B. Dahmus, A. J. Jones, A. Thiriez, and D. P. Sekulic, "Thermodynamic analysis of resources used in manufacturing processes," Environmental Science and Technology, vol. 43, no. 5, pp. 1584-1590, 2009.

[18] A. C. McKinnon, "Product-level carbon auditing of supply chains: environmental imperative or wasteful distraction?" International Journal of Physical Distribution \& Logistics Management, vol. 40, no. 1-2, pp. 42-60, 2010.

[19] S. Perry, J. Klemeš, and I. Bulatov, "Integrating waste and renewable energy to reduce the carbon footprint of locally integrated energy sectors," Energy, vol. 33, no. 10, pp. 1489-1497, 2008.

[20] D. Demailly and P. Quirion, "European Emission Trading Scheme and competitiveness: a case study on the iron and steel industry," Energy Economics, vol. 30, no. 4, pp. 2009-2027, 2008.

[21] I. T. Gutowsk, "The dynamic analysis of resources used in manufacturing processes," Environmental Science and Technology, vol. 43, pp. 1584-1590, 2009.

[22] G. Chryssolouris, Manufacturing Systems: Theory and Practice, Springer, New York, NY, USA, 1992.

[23] J.-B. Yang and D.-L. Xu, "On the evidential reasoning algorithm for multiple attribute decision analysis under uncertainty," IEEE Transactions on Systems, Man, and Cybernetics Part A: Systems and Humans, vol. 32, no. 3, pp. 289-304, 2002.

[24] T. L. Saaty, The Analytic Hierarchy Process, McGraw-Hill, New York, NY, USA, 1980. 


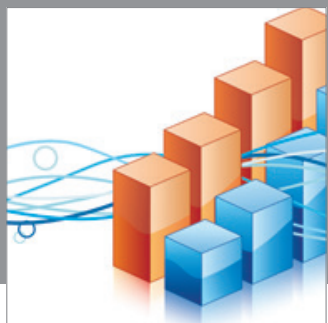

Advances in

Operations Research

mansans

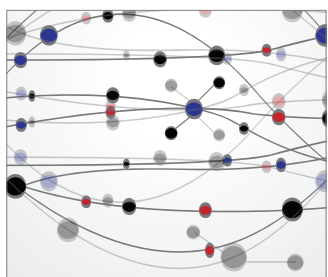

The Scientific World Journal
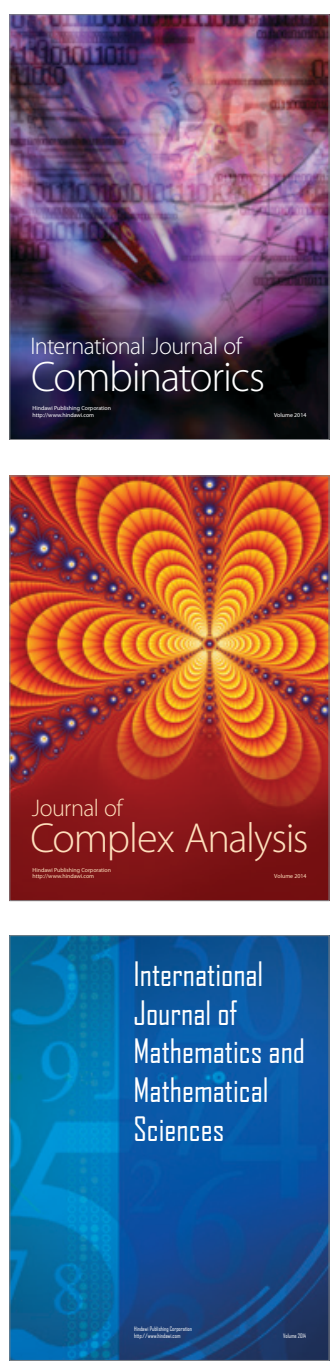
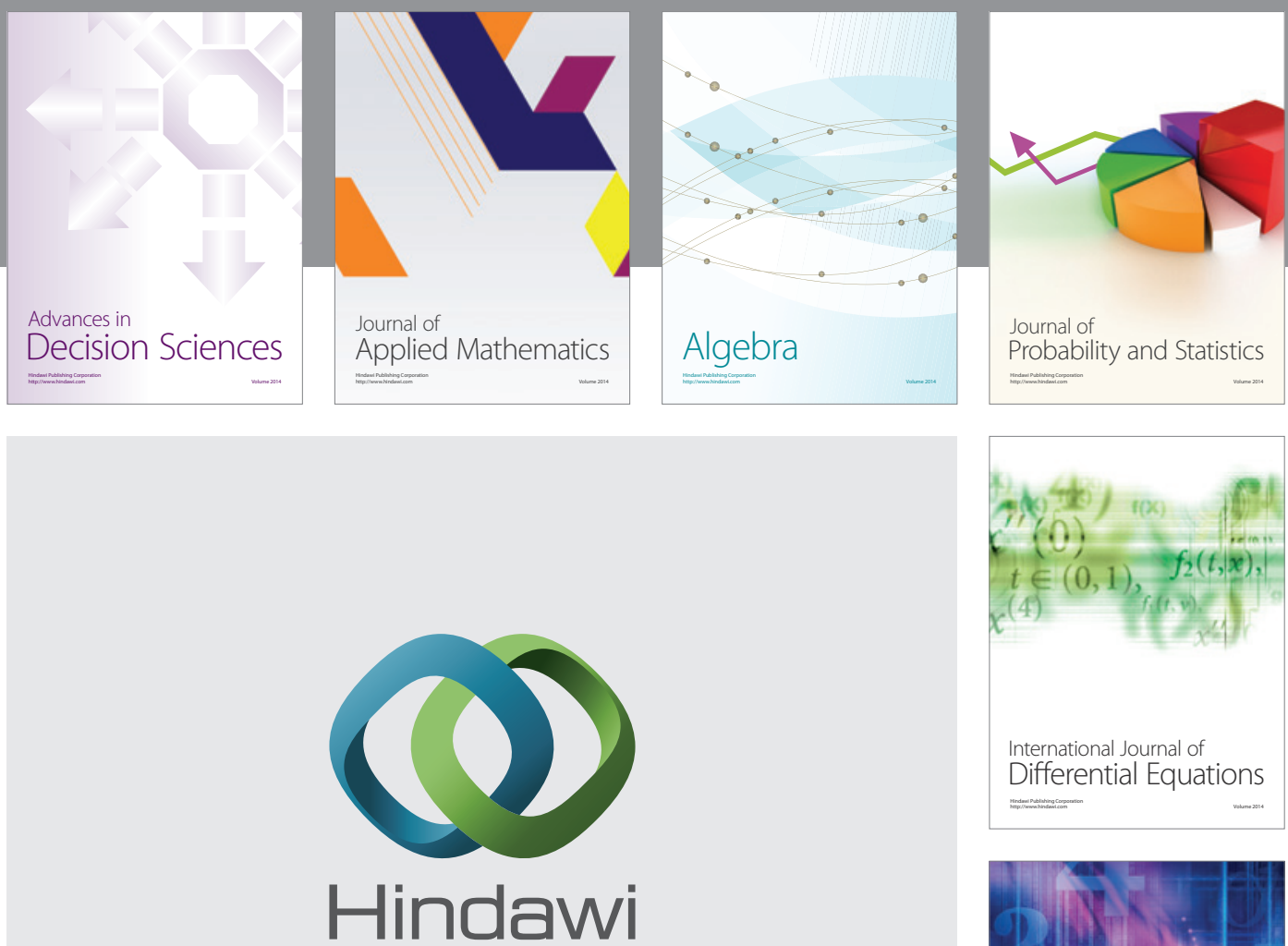

Submit your manuscripts at http://www.hindawi.com
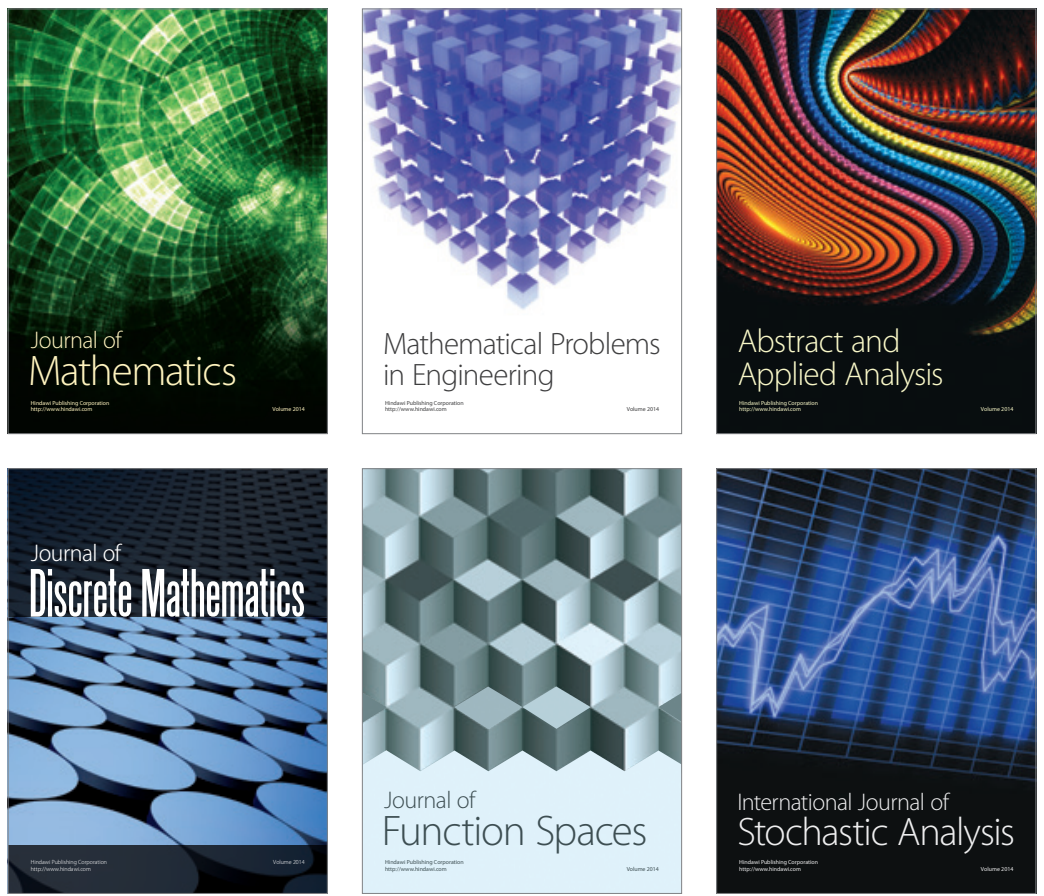

Journal of

Function Spaces

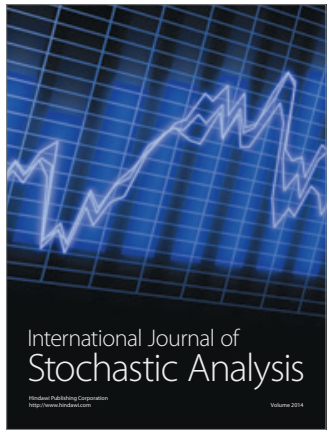

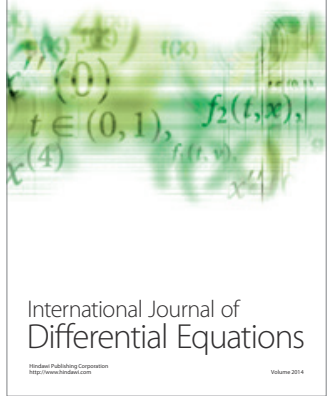
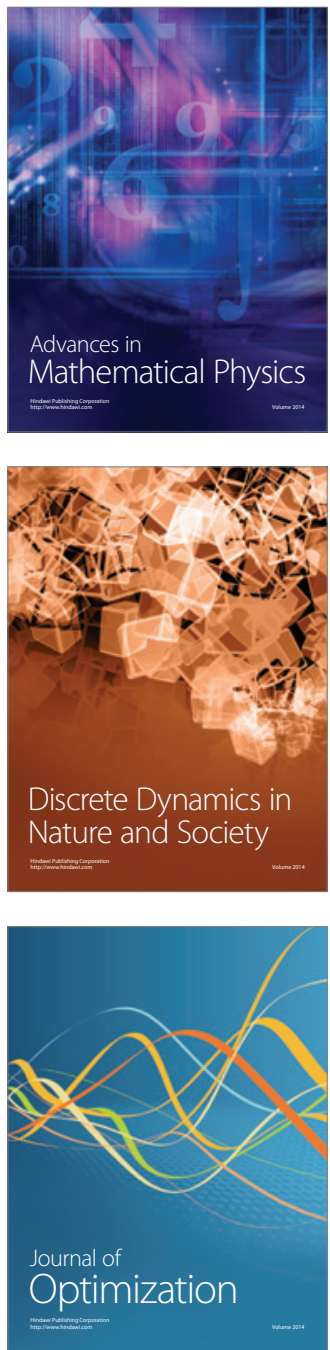